\title{
NOVAS ESPÉCIES DE LAURACEAE PARA A FLORA BRASILEIRA
}

João Batista Baitello1

Recebido em 14/04/00. Aceito em 20/09/01

RESUMO - (Novas espécies de Lauraceae para a flora brasileira), são descritas e ilustradas duas novas espécies de Ocotea Aublet: Ocotea cryptocarpa e Ocotea curucutuensis. As novas espécies ocorrem respectivamente nos Estados do Espírito Santo (município de Santa Tereza) e São Paulo (município de São Paulo), Brasil.

Palavras-chave - novas espécies, Lauraceae, Ocotea

ABSTRACT - (New Lauraceae species for the Brasilian flora), two new species of Ocotea Aublet is described and illustrated: Ocotea cryptocarpa and Ocotea curucutuensis. These new species occur, respectively, in the states of Espírito Santo (municipality of Santa Tereza) and São Paulo (municipality of São Paulo), Brazil.

Key-words - new species, Lauraceae, Ocotea

1. Instituto Florestal de São Paulo, C.P. 1322, CEP 01059-970. São Paulo (SP), Brasil; e-mail baitello@iflorestsp.br 


\section{Introdução}

Os inventários botânicos têm revelado que as Lauraceae estão entre as famílias mais importantes, mas, infelizmente, a identificação de suas espécies é tarefa das mais árduas.

Ocotea Aublet é o maior gênero da família Lauraceae na região Neotropical, com cerca de 350 espécies, a maioria nas Américas tropical e subtropical. Estima-se que no Brasil ocorra entre 120 a 160 espécies.

É um gênero muito variável servindo como depósito de espécies que não são prontamente acomodadas em outros gêneros (Werff, 1991). Segundo Rohwer (1986 e 1993) é o gênero menos definido da família.

$\mathrm{O}$ gênero caracteriza-se por flores trimeras bissexuadas, polígamas ou unissexuadas, 9 estames, estéreis nas flores pistiladas, anteras 4-loceladas (muito raramente 2-loceladas em poucas espécies da América Central), esporângios arranjados em dois pares sobrepostos ou raramente os locelos superiores entre os inferiores formando um arco fechado, filetes pouco mais longos que as anteras a ausentes, estames da terceira série com um par de glândulas na base dos filetes, glândulas em geral globosas ou reniformes, estaminódios da quarta série ausentes a conspícuos, nunca claramente sagitados, nas flores estaminadas ovário bem desenvolvido a ausente, fruto sobre cúpula de tamanho e forma variadas.

Os estudos das exsicatas da família Lauraceae, respectivamente para os Estados do Espírito Santo (Estação Biológica de Santa Tereza) e São Paulo (Parque Estadual da Serra do Mar), ambos no contexto da Mata Atlântica, revelaram duas novas espécies.

A primeira não tem paralelo com as espécies brasileiras conhecidas do gênero, pois, à maneira de Cryptocarya, o fruto é envolto totalmente pelo hipanto acrescente.

A segunda, está relacionada a Ocotea spixiana (Nees) Mez, do Brasil-Central e Minas Gerais.

\section{Material e Métodos}

O presente estudo deu-se com exsicatas da família Lauraceae dos Herbários SPSF (Herbário D. Bento Pickel - Instituto Florestal), PMSP (Prefeitura do Município de São Paulo) e MBML (Museu Botânico Mello-Leitão).

A nova espécie de São Paulo é resultado da intensificação de coletas promovidas pelo Projeto Temático da FAPESP - Flora Fanerogâmica do Estado de São Paulo e coletas botânicas em levantamentos florísticos realizados no Núcleo Curucutu em área de Mata Atlântica, pela equipe do Herbário PMSP (Prefeitura do Município de São Paulo) e Herbário D. Bento Pickel - SPSF (Instituto Florestal).

\section{Resultados e Discussão}

1) Ocotea cryptocarpa J. B. Baitello, sp. nov.

Arbor monoecia, 10-20m alta. Ramuli crassi, glabrescentes; gemma terminalis adpresse leuco-pubescens. Folia alterna, coriacea, obovata, apice late rotundata, emarginata, basi attenuata, revoluta, 5-10 x 2,5$4 \mathrm{~cm}$, subtus minuteque puberula, glabrescentia; nervii secundarii super et subtus elevati; reticulatio super et subtus laxa; petioli crassi, $0,8-1,1 \mathrm{~cm}$ longi, minuteque puberili, glabrescentes. Inflorescentiae axillares, subterminales, 3-6mm longae, minute adpresse pubescentes.

Flores hermaphroditi, 4-6mm diam., minute adpresse pubescentes, pedicellis ca. $2 \mathrm{~mm}$ longi, hypanthium fere urceolatum, intus glaberrimum; tepala fere ovata, intus minute papillosa et pubescentia; antherae exteriores quadrilocelatae, ovatae vel rotundatorectangulares, locellis per paria superpositis, filamento brevi; staminodia apice fere sagittata; pistillum ca. $2 \mathrm{~mm}$ longum, glaberrimum, stylo ovario paulo breviore. Fructus 2-2,5 x 2-2,5cm, globosus, lignosus, verruculosum, costatus, apice tepali rudimentis coronato ut in Cryptocarya. 


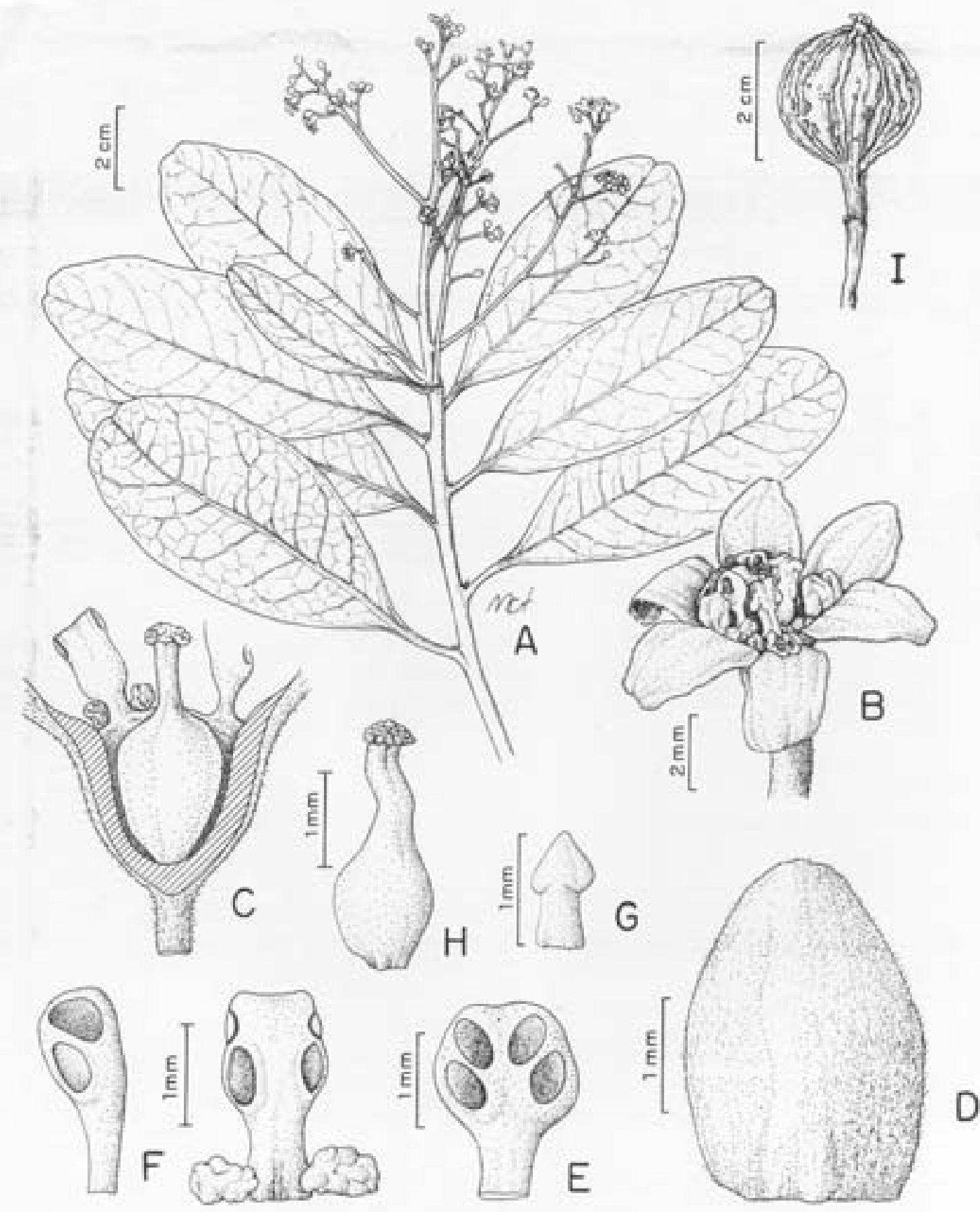

Figura 1. A-I. Ocotea cryptocarpa J.B. Baitello. A. ramo com flores; B. detalhe da flor; C. seção longitudinal do hipanto, envolvendo quase totalmente o ovário; D. tépala; E. estame 4-esporangiado das séries I e II; F. estame da série III em vistas ventral e lateral; G. estaminódio série IV; H. pistilo; I. fruto. A-H (Thomaz s.n., SPSF 18757); I. (Thomaz s.n., SPSF 18756). 
Holótipo: BRASIL. Espírito Santo, Município de Santa Tereza, Estação Biológica Santa Lúcia, alto de encosta, alt. 800m, fl., 13/I/1994, L.D. Thomaz s.n. (SPSF 18757). Isótipo (MBML).

Parátipos: BRASIL. Espírito Santo, Município de Santa Tereza, Estação Biológica Santa Lúcia, fr., 18/I/1995, L.D. Thomaz s.n. (SPSF 18756, MBML); fl., 15/II/1996, H.Q. Boudet Fernandes 3155 (MBML); fr., 17/I/1995, L.D. Thomaz s.n. (SPSF 18755, MBML); fr. 31/III/ 1998, E. Bausen 83 (MBML, SPSF).

Árvore monóica, $10-20 \mathrm{~m}$ alt. Râmulos robustos, glabrescentes, gema terminal até $1 \mathrm{~cm}$, apresso leuco-pubescente. Folhas alternas, coriáceas, obovadas, ápice arredondado, emarginado, base atenuada, revoluta, 5-10 x 2,5$4 \mathrm{~cm}$; face abaxial curto-puberulenta a glabrescente, nervuras laterais 6-9 pares, salientes em ambas as faces, reticulação laxa; pecíolo robusto, $0,8-1,1 \mathrm{~cm}$ compr., curtopuberulento a glabrescente. Inflorescências axilares, subterminais, $3-6 \mathrm{~cm}$ compr., curto apresso-pubescentes. Flores bissexuadas, 46mm diâm., curto apresso-pubescentes, pedicelo ca. $2 \mathrm{~mm}$, hipanto profundo largo a urceolado, glabro dentro; tépalas subovaladas, face interna finamente papilosa entremeada de pêlos esparsos; anteras externas 4-loceladas, ovaladas ou arredondado-retangulares, locelos sobrepostos aos pares, filete curto; estaminódio subsagitado no ápice; pistilo ca. $2 \mathrm{~mm}$ alt., glabro, ovário globoso-elíptico, estilete mais curto ou do mesmo comprimento que o ovário. Fruto 2-2,5 x 2-2,5cm, globoso, lenhoso, verruculoso, costado, coroado pelos rudimentos das tépalas, como em Cryptocarya.

Distribuição geográfica: Conhecida apenas pelos tipos coletados na Floresta Alto e Baixo Montana da Estação Biológica de Santa Lúcia, município de Santa Tereza (ES).

Ocotea cryptocarpa não tem paralelo no Brasil, pois nenhuma das espécies deste gênero conhecidas tem o fruto totalmente envolto pelo hipanto acrescente. Frutos deste tipo são conhe- cidos entre nós em Cryptocarya e Cassytha, dois gêneros 2-locelados e Ravensara, Dahlgrenodendron, Hypodaphnis e Eusideroxylon, não ocorrentes no Brasil.

Fruto completamente envolto pela cúpula é considerado avançado na família. $\mathrm{O}$ mesmo não se pode dizer das anteras 4-loceladas, um caráter primitivo. Esta combinação é a primeira registrada para o gênero no Brasil.

O epiteto refere-se ao fruto envolto pelo hipanto acrescente (cúpula).

2) Ocotea curucutuensis J.B. Baitello sp. nov.

Arbor vel arbuscula dioicia, 2-10m alta.

Folia rigide coriacea, adulta supra glabra, subtus manifeste ferrugineo-lanuginosa, 5-9 nervis lateralibus utroque costae, ellíptica, 7-15 x 2,5$5,5 \mathrm{~cm}$, apice breviter acuminata vel acuta; petioli crassi, $1-1,5 \mathrm{~cm}$ longi, glabrescentes, alati laminis decurentes. Inflorescentiae axillis foliorum juniorum ortae, infra gemmam terminalem, ferrugineo-lanuginosae, folia subaequans vel breviores, pedunculum robustum $1-5 \mathrm{~cm}$ longum. Flores masculi $8-12 \mathrm{~mm}$ diam., $5-7 \mathrm{~mm}$ alt. dense ferrugineo-lanuginosi, hypanthium obconicum, intus pubescens; tepala patentia, ovata, intus tomentosa; antherae omnes quadrilocellatae, locellis per paria superpositis, apice obtusae, emarginatae, filamenta breviora vel longiora; staminodia nulla; pistillum sterile, robustum stipitiforme, ca. 3,5mm longum, dense brevi-tomentosum. Flores feminei ut in masculi, hypanthio intus pubescens vel glabrescens, pistillum fertile robustum, dense brevitomentosum, 4mm longum, ovarium globosoellipsoideum, sensim in stylo attenuatum, stylo percrasso. Fructus late ellipticus vel late ovatus 2-2,5 x 1,5-2cm, dense brevi-tomentosi, fere velutini, cupula planiuscula, $7-10 \mathrm{~mm}$ late, margine hexalobatus.

Holótipo: BRASIL. São Paulo, Município de São Paulo, Parque Estadual Serra do Mar, Núcleo Curucutu, fl. ?, 06/III/1998, P. Affonso 168 (SPSF). Isótipo (PMSP).

Parátipos: BRASIL. São Paulo, Município de 


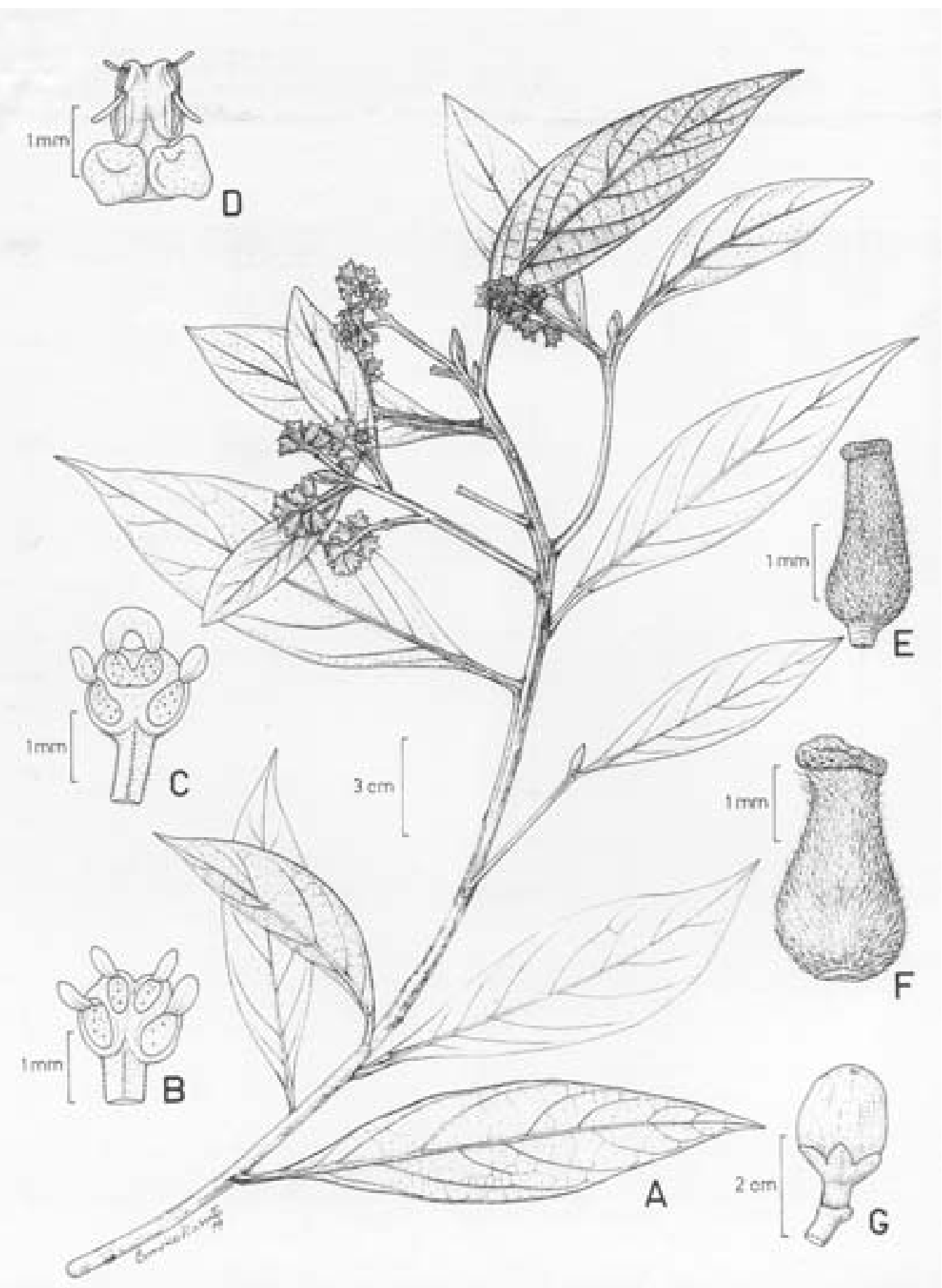

Figura 2. A-G. Ocotea curucutuensis J.B. Baitello. A. ramo com flores; B. estame das séries I e II; C. estame das séries I e II evidenciando a fusão dos esporângios superiores; D. estame da série III; E. pistilóide; F. pistilo; G. fruto. A e F (Affonso 168); B-E (Affonso 366); G (Alonso 64) 
São Paulo, Parque Estadual Serra do Mar, Núcleo Curucutu, fl. 18/III/1999, P. Affonso 366 (PMSP, SPSF); fr., 24/I/1995, M. Alonso 64 (SPSF).

Árvore ou arvoreta dióica, 2-10m alt. Folhas rígido-coriáceas, face adaxial glabra, a abaxial ferrugíneo-lanuginosa, nervuras laterais 5-9 pares, elíptica, 7-15 x 2,5-5,5cm, ápice brevemente acuminado ou agudo; pecíolo crasso, 1-1,5cm comp., glabrescente, decorrente. Inflorescências nas axilas das folhas jovens abaixo da gema terminal, ferrugíneolanuginosas, menores a subiguais às folhas, pedúnculo robusto, $1-5 \mathrm{~cm}$ compr. Flores estaminadas, $8-12 \mathrm{~mm}$ diâm., 5-7mm alt., denso-ferrugíneo-lanuginosas, hipanto obcônico, internamente pubescente; tépalas patentes, ovaladas, face interna tomentosa; anteras 4loceladas, locelos superpostos aos pares, locelos superiores às vezes fusionados, ápice obtuso, emarginado, filetes mais curtos ou mais longos que as anteras; estaminódios ausentes; pistilóide, robusto, estipitiforme, ca. $3,5 \mathrm{~mm}$ compr., denso-curto-tomentoso.

Flores pistiladas como as estaminadas, hipanto pubescente ou glabrescente dentro, pistilo robusto, denso-curto-tomentoso, $4 \mathrm{~mm}$ compr., ovário globoso-elipsóide, atenuando para o estilete percrasso. Fruto largo-elíptico ou largo-ovalado, 2-2,5 x 1,5-2cm, denso-curtotomentoso, quase velutino, cúpula plana, 7$10 \mathrm{~mm}$ larg., margem hexalobada.

Distribuição geográfica: conhecida apenas pelos tipos coletados na Floresta Nebular de baixa estatura associada a Campos Montanos do Parque Estadual da Serra do Mar, Núcleo Curucutu, extremo sul do município de São Pau- lo. No seu habitat natural $O$. curucutuensis assemelha-se a Nectandra oppositifolia com suas folhas fortemente ferrugíneas na face abaxial.

Ocotea curucutuensis é afim de O. spixiana por suas flores densamente pubescentes, de grandes dimensões para a família (ca. 8-12 x 5-7 $\mathrm{mm}$ ), pistilo e pistilóide muito robustos, talvez os maiores conhecidos para o gênero. Diferem especialmente quanto ao tamanho do fruto que é 2 a 4 vezes maior em $O$. curucutuensis, além do pecíolo mais robusto e da lâmina foliar mais rígida.

Diferem ainda quando à pubescência da face abaxial da folha, pois em O. curucutuensis o indumento denso-lanuginoso cobre totalmente a epiderme, o que não ocorre com $O$. spixiana, cujo indumento é tomentoso, deixando a epiderme apenas parcialmente encoberta.

Nenhuma das coleções de $O$. spixiana, de diferentes origens, apresenta a face abaxial da folha fortemente ferrugíneo-avermelhada como em O. curucutuensis.

\section{Referências Bibliográficas}

Rohwer, J.G. 1986. Prodromus einer monographie der Gattung Ocotea Aublet (Lauraceae), sensu lato. Mitt. Allg. Bot. Hamburg, 20: 3-278.

Rohwer, J.G. 1993. Lauraceae. In, K. Kubitzki, J.G. Rohwer \& V. Bittrich (eds.). The families and genera of vascular plants. Flowering plants. Dicotyledons. Berlin, Springer-Verlag, 2: 336-391.

Werff. H. van der. 1991. A key to the genera of Lauraceae in the new world. Ann. Missouri Bot. Gard. 78: 377-387. 